\title{
Leptocybe invasa em Eucalyptus sp. no estado do Rio Grande do Sul, Brasil
}

\author{
Leptocybe invasa Eucalyptus sp. in the state of Rio Grande do Sul, Brazil
}

\author{
Juliana Garlet ${ }^{\mathrm{I}}$ Ervandil Corrêa Costa ${ }^{\mathrm{II}}$ Jardel Boscardin ${ }^{\mathrm{II}}$ Gilmar DepontiII \\ Clovis Roberto Shwengber ${ }^{\text {III }}$ Leonardo Mortari Machado ${ }^{I I}$
}

\begin{abstract}
RESUMO
O presente estudo relata o ataque da vespa-dagalha do eucalipto Leptocybe invasa Fisher \& LaSalle, 2004 (Hymenoptera: Eulophidae) no Estado do Rio Grande do Sul, Brasil. As formas imaturas de $\mathbf{L}$. invasa induzem o crescimento de galhas que podem levar ao desfolhamento de árvores de eucalipto.

Palavras-chave: entomologia florestal, galha, Myrtaceae, vespada-galha.

\section{ABSTRACT}

The present study reports the attack of the eucalyptus gall wasp Leptocybe invasa Fisher \& LaSalle, 2004 (Hymenoptera: Eulophidae) in the state of Rio Grande do Sul, Brazil. The immature stages of $\boldsymbol{L}$. invasa induce the growth of galls that can lead to defoliation of eucalyptus trees.
\end{abstract}

- NOTA -
Key words: forest entomology, gall, Myrtaceae, gall wasp.

A eucaliptocultura atualmente ocupa posição de destaque no agronegócio brasileiro, pois abrange cerca de cinco milhões de hectares, a maior área plantada com florestas comerciais do Brasil (ABRAF, 2012). Espécies de Eucalyptus (Myrtaceae) são cultivadas para produção de celulose, carvão, madeira para as mais diversas finalidades, óleos para indústria farmacêutica, além de servir como ornamentação, barreiras quebra-vento, fornecedoras de néctar e pólen para a apicultura, entre outros (HASSE, 2006). O plantio de Eucalyptus é também boa opção econômica para pequenos produtores em cultivos em consórcios silvipastoris ou agroflorestais.

O gênero Eucalyptus, nativo do continente australiano, adaptou-se bem às condições climáticas brasileiras, o que possibilitou seu plantio em larga escala. No entanto, o aumento da área cultivada no país favorece 0 ataque de espécies-praga especializadas desta cultura de ciclo longo, plantada em monocultivos, onde é grande a oferta de alimento e a população de inimigos naturais é reduzida pela simplificação do ecossistema.

A introdução de insetos-praga exóticos como o psilídeo-de-concha Glycaspis brimblecombei Moore, 1964 (Hemiptera: Psyllidae), o pecevejobronzeado Thaumastocoris peregrinus Carpintero e Dellapé, 2006 (Hemiptera: Thaumastocoridae), registrados em quase todos os estados brasileiros, e a recente introdução da vespa-da-galha Leptocybe invasa Fisher \& LaSalle, 2004 (Hymenoptera: Eulophidae), são os principais problemas entomológicos da eucaliptocultura nacional na atualidade (FURTADO \& WILCKEN, 2012).

L. invasa é originária do continente australiano e há relatos de sua introdução na África do Sul, Argélia, Camboja, Espanha, França, Grécia, Índia, Irã, Iraque, Israel, Itália, Jordânia, Líbano, Marrocos, Nova Zelândia, Portugal, Quênia, Síria, Tailândia, Tanzânia, Tunisia, Turquia, Uganda e Vietnã (MENDEL et al., 2004; FAO, 2009, NYEKO

\footnotetext{
${ }^{\mathrm{I}}$ Curso de Engenharia Florestal, Universidade do Oeste de Santa Catarina (UNOESC), Rua Dirceu Giordani, nº 696, 89820-000, Xanxerê, SC, Brasil. E-mail: julianagarlet@yahoo.com.br. Autor para correspondência.

IIDepartamento de Defesa Fitossanitária, Universidade Federal de Santa Maria (UFSM), Santa Maria, RS, Brasil.

IIIAssociação Riograndense de Empreendimentos de Assistência Técnica e Extensão Rural (Emater), Associação Sulina de Crédito e Assistência Rural (Ascar), Santa Maria, RS, Brasil. 
et al., 2009; DHAHRI \& JAMAA, 2010; HASSAN, 2012). Na América do Sul, foi registrada pela primeira vez no Brasil em 2008 e, posteriormente, na Argentina (2009) e no Uruguai (2011) (WILCKEN \& BERTI FILHO, 2008; AQUINO et al., 2011; FURTADO \& WILCKEN, 2012).

No Brasil, L. invasa foi primeiramente encontrada em mudas de eucalipto em viveiro e em árvores adultas de clones híbridos de $\boldsymbol{E}$. camaldulensis $\mathrm{x}$ E. grandis no nordeste da Bahia (WILCKEN \& BERTI FILHO, 2008) e, posteriormente, registrada nos estados do Maranhão, Tocantins, São Paulo, Minas Gerais, Paraná e Mato Grosso do Sul (MAGISTRALI et al., 2010; FURTADO \& WILCKEN, 2012; QUEIROZ et al. 2012). Assim, este é o primeiro relato de ocorrência de $\boldsymbol{L}$. invasa em eucalipto no Rio Grande do Sul.

Em janeiro de 2013, sua ocorrência foi verificada em dois hectares de Eucalyptus sp. de dois anos e cinco meses de idade, plantados em sistema silvipastoril, em renques de linhas triplas, no espaçamento $2 \mathrm{~m}$ x $2 \mathrm{~m}$ e $18 \mathrm{~m}$ de distância entre renques, na localidade de São Marcos (28³0'55'”S e 5556'21’'W), no município de São Borja, Rio Grande do Sul. Foram coletados ramos das plantas atacadas e o material, devidamente embalado, em sacos de plástico, acondicionado em caixa de isopor, foram encaminhados ao Laboratório de Entomologia Florestal da Universidade Federal de Santa Maria, Santa Maria, RS. Folhas com galhas foram depositadas em cinco placas tipo “Gerbox” e mantidas em sala de criação, com temperatura controlada de $25^{\circ} \mathrm{C}$ e umidade relativa do ar de $65 \%$ até a emergência de 53 adultos, que foram identificados por comparação com a descrição de $\boldsymbol{L}$. invasa (MENDEL et al.,2004). A forma de introdução dessa vespa no Rio Grande do Sul é desconhecida e, hipoteticamente, pode ter sido causada pelo uso de mudas contaminadas ou através do transporte do inseto por correntes de ar provenientes da Argentina, onde sua presença é constatada, cuja fronteira dista cerca de $2 \mathrm{~km}$.

As plantas atacadas por $\mathbf{L}$. invasa apresentavam indução de galhas nas nervuras principais das folhas, nos pecíolos, galhos e em alguns casos no tronco. $\mathrm{O}$ ataque foi observado em todas as partes da planta, o que ocasionou dobramento e secamento da maioria das folhas, sendo que o ataque foi constatado em cerca de 90\% (1.266 plantas) das árvores do plantio avaliado. Destaca-se a severidade do ataque observado e o fato dessa espécie ser encontrada agora em regiões com clima frio, visto que os relatos anteriores, no Brasil, foram principalmente no sudeste e nordeste, demonstrando a facilidade de adaptação de $\boldsymbol{L}$. invasa espécie, aumentando, assim, as regiões onde este inseto-praga pode causar significativo dano econômico. FERNANDES \& CARNEIRO (2009) destacaram que insetos galhadores são capazes de modificar os padrões de crescimento da planta hospedeira e alterar a natureza do tecido vegetal, o que prejudica seu desenvolvimento, podendo levá-la à morte.

L. invasa, ataca principalmente, mudas em viveiro e plantas jovens de eucalipto e provoca galhas semelhantes a um inchaço na nervura principal das folhas, nos pecíolos e/ou em ramos novos (QUEIROZ et al., 2012). Seus adultos, de coloração marrom-escura, brilhante, medem entre 1,1 e 1,4mm de comprimento; sua reprodução se dá por partenogênese telítoca (são poucos os registros de machos em plantios florestais), o que aumenta seu potencial de crescimento populacional - pode ocorrer a sobreposição de duas ou três gerações por ano. A fêmea oviposita de 80 a 100 ovos sob a epiderme de gemas apicais, nervuras de folhas e ramos, o que induz a formação de galhas, no interior das quais se desenvolvem suas larvas. O ciclo de vida do inseto é longo, de cerca de 130 dias, dos quais apenas seis na fase adulta (MENDEL et. al., 2004).

MENDEL et al. (2004) classificaram o desenvolvimento das galhas em cinco fases. A primeira ocorre nas duas semanas pós oviposição e ao seu final as galhas são facilmente reconhecíveis por sua forma esférica, facilmente separada das demais, de cor verde brilhante; na segunda, caracterizada pelo aumento de seu volume, as galhas atingem seu tamanho máximo, de aproximadamente $2,7 \mathrm{~mm}$ de largura; na terceira, a cor da galha muda para rosada, mantendo o seu brilho típico; na quarta, ocorre a perda do brilho da superfície das galhas e a cor muda para vermelho-escuro; e, na quinta, ocorre a emergência das vespas.

NADEL \& SLIPPERS (2011) afirmaram que Eucalyptus botryoides Sm., Eucalyptus bridgesiana R. Baker, Eucalyptus camaldulensis Dehn., Eucalyptus globulus Labill., Eucalyptus robusta Sm., Eucalyptus saligna Sm., Eucalyptus tereticornis Sm., Eucalyptus urophylla S.T. Blake e E. viminalis Labill. são mais susceptíveis ao ataque da vespa-de-galha. QUANG THU et al. (2009) e ZHU FANG-LI (2012) destacaram ainda que os danos mais severos de $\boldsymbol{L}$. invasa são encontrados principalmente em plantios jovens das espécies: E. camaldulenis, Eucalyptus grandis W. Hill e E. tereticornis.

Para HARISH et al. (2010), a forma mais viável de controle para $\boldsymbol{L}$.invasa é através de parasitoides da Ordem Hymenoptera, encontrados constantemente nos levantamentos populacionais 
do inseto-praga nos diferentes países onde foi introduzida, destacando-se os gêneros Aprostocetus sp. e Megastigmus sp. KELLY et al. (2012) destacaram ainda que o controle químico da vespa-da-galha não é viável, pois o inseto completa seu desenvolvimento dentro da galha. Segundo esses autores, as possíveis formas de controle seriam o plantio de espécies resistentes ou menos susceptíveis, em áreas com histórico de ataque da espécie-praga, além de adoção do controle biológico com himenópteros parasitoides.

\section{AGRADECIMENTOS}

Aos Engenheiros e Técnicos da Emater/RS-Ascar, Escritórios Regionais de Santa Maria-RS e Bagé-RS, pela contribuição ao presente estudo. Ao Sr. Emiliano Batista Lopes pela acolhida e auxílio prestados.

\section{REFERÊNCIAS}

ABRAF (ASSOCIAÇÃO BRASILEIRA DE PRODUTORES DE FLORESTAS PLANTADAS). Anuário estatístico da Abraf 2012. Disponível em: <http://www.abraflor.org.br/estatisticas/ ABRAF08-BR.pdf>. Acesso em: 25 jan. 2013.

AQUINO, D.A. et al. "Avispa de la agalla del eucalipto”, Leptocybe invasa Fischer \& LaSalle (Hymenoptera: Eulophidae: Tetrastichinae) en Argentina. Revista de Investigaciones Agropecuarias, v.37, n.2, p.159-164, 2011. Disponível em: <http://www.cabi.org/isc/FullTextPDF/2011/20113290054.pdf>. Acesso em: 25 jan. 2013.

DHAHRI, S.; JAMAA, M.L.B. First record of Leptocybe invasa and Ophelimus maskelli eucalyptus gall wasps in Tunisia. Tunisian Journal of Plant Protection, v.5, n.2, p.229-234, 2010. Disponível em: <http://www.iresa.tn/tjpp/tjpp10/8BenJamaa2x. pdf $>$. Acesso em: 4 mar. 2013.

FAO. Global review of forest pests and diseases. (On-line). Roma: FAO, 2009. 222p. Disponível em: <http://www.fao.org/ docrep/011/i0640e/i0640e00.htm>. Acesso em: 25 jan. 2013.

FERNANDES, G.W.; CARNEIRO, M.A. Insetos galhadores. In: PANIZZI, A.R.; PARRA, J.R.P. Bioecologia e nutrição de insetos: base para o manejo integrado de pragas. Brasília: EMBRAPA, 2009. Cap.15, p.595-636.

FURTADO, E.L; WILCKEN, C.F. Priorização de registro de produtos. Disponível em: <http://www.agricultura.gov. br/arq_editor/file/camaras_setoriais/Florestas_plantadas/1RE/ App_Prioriza\%C3\%A7a\%20_de\%20agroquimicos_UNESP.pdf > . Acesso em: 25 jan. 2013.
HASSAN, F.R. First record of the eucalyptus gall wasp, Leptocybe invasa Fisher and La Salle (Hymenoptera: Eulophidae), in Iraq. Acta Agrobotanica, v.65, n.3, p.93-98, 2012.

HASSE, G. Eucalipto: histórias de um imigrante vegetal. Porto Alegre: JA Editores, 2006. 127p.

HARISH , N.K. et al. Release and recovery of parasitoids in eucalyptus against gall wasp, Leptocybe invasa (Hymenoptyera: Eulophidae) under green house. Karnataka Journal of Agricultural Sciences, v.23, n.1, p.91-92, 2010.

KELLY, J. et al. Selitrichodes neseri n. sp., a new parasitoid of the eucalyptus gall wasp Leptocybe invasa Fisher \& La Salle (Hymenoptera: Eulophidae: Tetrastichinae). Zootaxa, n.3333, p.50-57, 2012.

MAGISTRALI, I.C. et al. Registro da microvespa-da-galha em plantios de eucaliptos, no Estado do Maranhão. In: JORNADA ACADÊMICA INTEGRADA, 25., 2010, Santa Maria, RS. Anais... Santa Maria: UFSM, 2010. p.1-1. Disponível em: <http:// portal.ufsm.br/jai2010/anais/trabalhos/trabalho_1041236389. htm>. Acesso em: 25 jan. 2013.

MENDEL, Z. et al. Taxonomy and biology of Leptocybe invasa gen. \& sp. n. (Hymenoptera: Eulophidae), an invasive gall inducer on Eucalyptus. Australian Journal of Entomology, v.43, p.101-113, 2004.

NADEL, R.; SLIPPERS, B. Leptocybe invasa, the blue gum chalcid wasp. Information Sheet, 2011. 5p. Disponível em: <http://www.forestry.co.za/uploads/File/home/notices/2011/ ICFR\%20IS01-2011gallwasp.pdf>. Acesso em: 25 jan. 2013.

NYEKO, P. et al. Eucalyptus infestation by Leptocybe invasa in Uganda. African Journal of Ecology, v.47, p.299-307, 2009. Disponível em: <http://onlinelibrary.wiley.com/doi/10.1111/ j.1365-2028.2008.01004.x/pdf>. Acesso em: 4 mar. 2013.

QUANG THU, P. et al. Susceptibility of 18 eucalypt species to the gall wasp Leptocybe invasa in the nursery and young plantations in Vietnam. ScienceAsia, v.35, p.113-117, 2009. Disponível em: <http://researchrepository.murdoch.edu.au/2963/1/susceptability_ of_eucalypt_species.pdf>. Acesso em: 13 mar. 2013.

QUEIROZ, D.L et al. Dispersão de Leptocybe invasa no Brasil. In: CONGRESSO BRASILEIRO DE ENTOMOLOGIA, 24., 2012, Curitiba, PR. Anais... Curitiba: SEB/UFPR, 2012. V.1, p.246-246. Disponível em: <http://ainfo.cnptia.embrapa.br/ digital/bitstream/item/66630/1/Queiroz-et-al-2012-Leptocybe. pdf $>$. Acesso em: 24 jan. 2013.

ZHU FANG-LI, R.S. et al. The abundance and population dynamics of Leptocybe invasa (Hymenoptera: Eulophidae) galls on Eucalyptus spp. in China. Journal of Integrative Agriculture, v.11, n.12, p.2116-2123, 2012.

WILCKEN, C.F.; BERTI FILHO, E. Vespa-da-galha do eucalipto (Leptocybe invasa) (Hymenoptera: Eulophidae): nova praga de florestas de eucalipto no Brasil. Alerta IPEF, 11p. Disponível em: <http://www.ipef.br/protecao/alerta-leptocybe.invasa.pdf > . Acesso em: 23 jan. 2013. 